\title{
Review Article \\ Sedation of Newborn Infants for the INSURE Procedure, Are We Sure?
}

\author{
Ellen H. M. de Kort, ${ }^{1,2}$ Irwin K. M. Reiss, ${ }^{1}$ and Sinno H. P. Simons ${ }^{1}$ \\ ${ }^{1}$ Division of Neonatology, Department of Pediatrics, Erasmus MC-Sophia Children's Hospital, Dr. Molewaterplein 60, \\ 3015 GJ Rotterdam, The Netherlands \\ ${ }^{2}$ Máxima Medical Center, De Run 4600, DB 5504, Veldhoven, The Netherlands
}

Correspondence should be addressed to Ellen H. M. de Kort; e.dekort@telfort.nl

Received 17 October 2013; Accepted 28 November 2013

Academic Editor: Allegaert Karel

Copyright ( 2013 Ellen H. M. de Kort et al. This is an open access article distributed under the Creative Commons Attribution License, which permits unrestricted use, distribution, and reproduction in any medium, provided the original work is properly cited.

\begin{abstract}
Background. Neonatal intubation is a stressful procedure that requires premedication to improve intubation conditions and reduce stress and adverse physiological responses. Premedication used during the INSURE (INtubation, SURfactant therapy, Extubation) procedure should have a very short duration of action with restoration of spontaneous breathing within a few minutes. Aims. To determine the best sedative for intubation during the INSURE procedure by systematic review of the literature. Methods. We reviewed all relevant studies reporting on premedication, distress, and time to restoration of spontaneous breathing during the INSURE procedure. Results. This review included 12 studies: two relatively small studies explicitly evaluated the effect of premedication (propofol and remifentanil) during the INSURE procedure, both showing good intubation conditions and an average extubation time of about 20 minutes. Ten studies reporting on fentanyl or morphine provided insufficient information about these items. Conclusions. Too little is known in the literature to draw a solid conclusion on which premedication could be best used during the INSURE procedure. Both remifentanil and propofol are suitable candidates but dose-finding studies to detect effective nontoxic doses in newborns with different gestational ages are necessary.
\end{abstract}

\section{Introduction}

Endotracheal intubation is a frequently performed procedure in the neonatal intensive care unit (NICU) [1]. It is a stressful procedure associated with pain and adverse physiological responses when the neonate is awake. Adverse effects include hypoxia, bradycardia, systemic hypertension, and increased intracranial pressure with a potential risk of intraventricular hemorrhage, especially in preterm infants [2-6]. Intubation without the use of premedication may lengthen the procedure, require a greater number of attempts [4-6], and cause traumatic damage to the face, eyes, tongue, gums, and glottic structures $[6,7]$. With this in mind, clinicians have started to routinely administer premedication $[2-4,8-11]$. However, there is still no consensus about the best drugs for neonatal intubations $[12,13]$.

The most frequent reason for intubation in preterm neonates is surfactant replacement therapy for respiratory distress syndrome (RDS). Incidence of RDS is $92 \%$ in $24-25$ weeks, $88 \%$ in $26-27$ weeks, $76 \%$ in $28-29$ weeks, and $57 \%$ in 30-31 weeks. Starting early with nasal continuous positive airway pressure (nCPAP) can reduce the need for surfactant replacement therapy in RDS by $50 \%$ [14]. Historically, surfactant was administered via a tracheal tube during mechanical ventilation. As mechanical ventilation may damage the pulmonary system and cause bronchopulmonary dysplasia (BPD), new techniques have been introduced to shorten duration of mechanical ventilation as much as possible. In the INSURE (INtubation, SURfactant administration, immediate Extubation) method infants are endotracheally intubated only for surfactant administration and are extubated immediately thereafter and put on nCPAP again. A Cochrane review in 2008 showed that the INSURE method significantly decreased the need for mechanical ventilation (relative risk (RR) 0.72, 95\% confidence interval (CI) 0.590.87 ), the incidence of BPD (RR $0.68,95 \%$ CI $0.57-0.79$ ) and the incidence of air leak syndromes (RR $0.52,95 \%$ CI 0.28 0.96) [15]. 
Intubation in the context of the INSURE procedure still requires the administration of premedication. However, rapid recovery of the respiratory drive is essential for the success of the INSURE procedure. As extubation should take place within several minutes after surfactant administration, the sedative agent used must have a very short duration of action. There is no consensus about what agent is most suitable as premedication for INSURE procedures. The goal of this paper is to determine the most appropriate sedative for neonatal intubation during the INSURE procedure by reviewing the literature.

\section{Methods}

Literature searches in Pubmed and EMBASE were performed to obtain all publications evaluating the effect of premedication for intubation during the INSURE procedure. We searched for information about the intubation conditions, the number of attempts needed for successful intubation, and mainly the time to awakening and extubation. The initia lsearch strategy involved the following keywords: "intubation, intratracheal" (MeSH), "premedication" (MeSH), and INSURE, with the limit newborn: birth-1 month. This search strategy revealed only 2 relevant publications.

Therefore we performed an additional search strategy for all publications describing the INSURE procedure and screening these publications for the following information: premedication used, dose of premedication, intubation conditions, number of attempts needed for successful intubation, time to restoration of sufficient breathing pattern, time to extubation, time to start nasal respiratory support, INSURE failure, intractable apnea as a reason for INSURE failure, and time window between extubation and INSURE failure. This search strategy involved the following keywords: "pulmonary surfactants" [MeSH], "respiratory distress syndrome, newborn" [MeSH], "positive pressure respiration" [MeSH], "continuous positive airway pressure" [MeSH], "infant, newborn" [MeSH], and "INSURE" in different combinations. Because the first publication describing the INSURE procedure appeared in 1990, publications in the time frame between January 1990 and June 2013 were sought. Because reviews describing the INSURE procedure do not usually provide any new data about premedication and its effects, we excluded reviews. Reference lists of publications describing the INSURE procedure were screened for other useful publications. Publications in the English, Dutch, French, and German languages were included. The full text of each report describing the INSURE procedure was screened for the abovementioned information.

\section{Results}

The overall literature search yielded 12 studies suitable for our review. Only 2 publications, both by Welzing et al., explicitly evaluated the effect of premedication for intubation during the INSURE procedure, that is, remifentanil and propofol, respectively $[16,17]$. The search strategy for publications describing the INSURE procedure revealed 36 publications.
We excluded 24 studies, 5 because they were written in another language (Danish, Swedish, and Chinese), 2 because any premedication before intubation clearly was not given, and 17 because they did not provide any information about the used premedication. Thus, 10 additional publications were included, next to both studies of Welzing et al. The following sedatives were evaluated: remifentanil, propofol, fentanyl, morphine, and a combination of morphine and pentobarbital. Characteristics of the studies regarding the INSURE procedure are summarized in Table 1 and detailed information about the effects and side-effects of the used premedication is provided in Table 2.

3.1. Remifentanil. In the study of Welzing et al. a total of 21 preterm infants received $10 \mu \mathrm{g} / \mathrm{kg}$ atropine and $2 \mu \mathrm{g} / \mathrm{kg}$ remifentanil prior to intubation. Fifteen patients $(71 \%)$ were intubated at the first attempt and 6 patients (29\%) at the second attempt. First failed attempts were ascribed to inexperience of residents in training and not to insufficient sedation. Intubation conditions were excellent in 14 patients (67\%) and good in 7 patients (33\%). No serious side effects occurred. nCPAP could be started, a mean of 10.9 minutes (range 1-30 minutes) after surfactant administration, and mean time to extubation was 42.4 minutes (range 1-330 minutes) [16].

3.2. Propofol. A pilot study of Welzing et al. evaluated the effect of propofol as premedication before intubation during the INSURE procedure. This pilot was supposed to continue for 1 year but was stopped prematurely because of significant problems with arterial hypotension. Thirteen preterm infants underwent the INSURE procedure and received $10 \mu \mathrm{g} / \mathrm{kg}$ atropine and $1 \mathrm{mg} / \mathrm{kg}$ propofol. Intubation was successful at the first attempt in 9 patients (69\%) and at the second attempt in 4 patients (31\%). First failed attempts were ascribed to inexperience of residents in training. Intubation conditions were excellent in five, good in six, and inadequate in two patients, respectively. Propofol gave only a short period of respiratory depression and nCPAP could be started as a mean of 25 minutes ( 2 to 120 minutes) after surfactant administration. One patient needed reintubation after INSURE because of inadequate respiratory drive. In 5 of 13 patients significant arterial hypotension was observed [17].

3.3. Morphine. Five of the 10 additionally included publications concerned morphine monotherapy in a dosage of 100 or $200 \mu \mathrm{g} / \mathrm{kg}$ [18-22]. The use of Naloxone was optional in most studies [18, 19, 21], standard practice in one study [22], and not mentioned in one study [20]. None of these 5 studies provided details on intubation conditions and number of attempts for successful intubation. The studies of Van den Berg et al. and Flor-de-Lima et al. did not address time to restoration of spontaneous breathing and INSURE failure because of insufficient breathing or apnea $[18,22]$. In the study of Cherif et al., all patients were extubated within $6.3 \pm 1.7$ minutes (range 5-12 minutes) after surfactant administration. However, INSURE failed in 35 patients (32.1\%) but reasons for this failure and the time frame between extubation and INSURE failure were not mentioned [20]. Verder et al. did not 


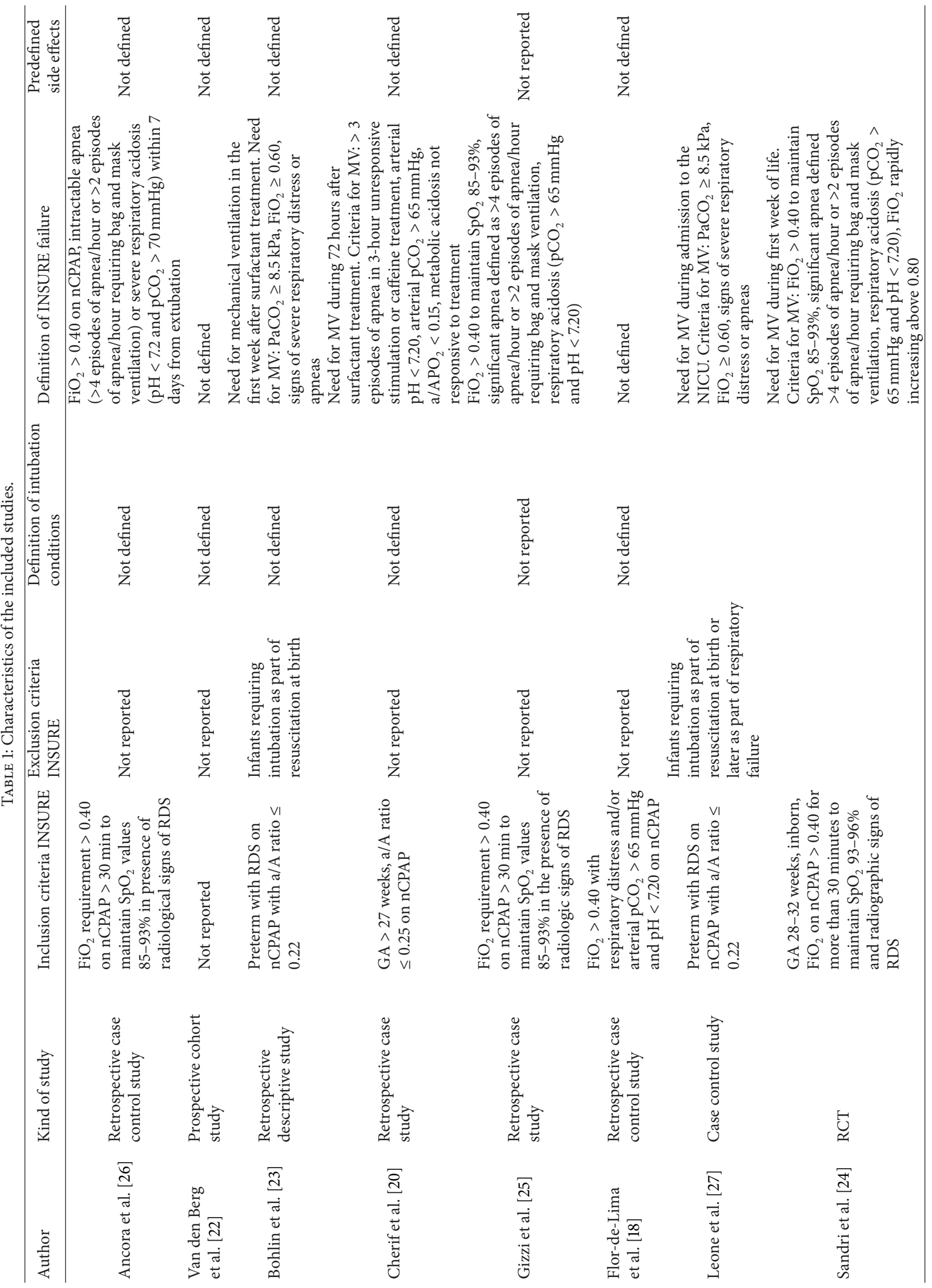




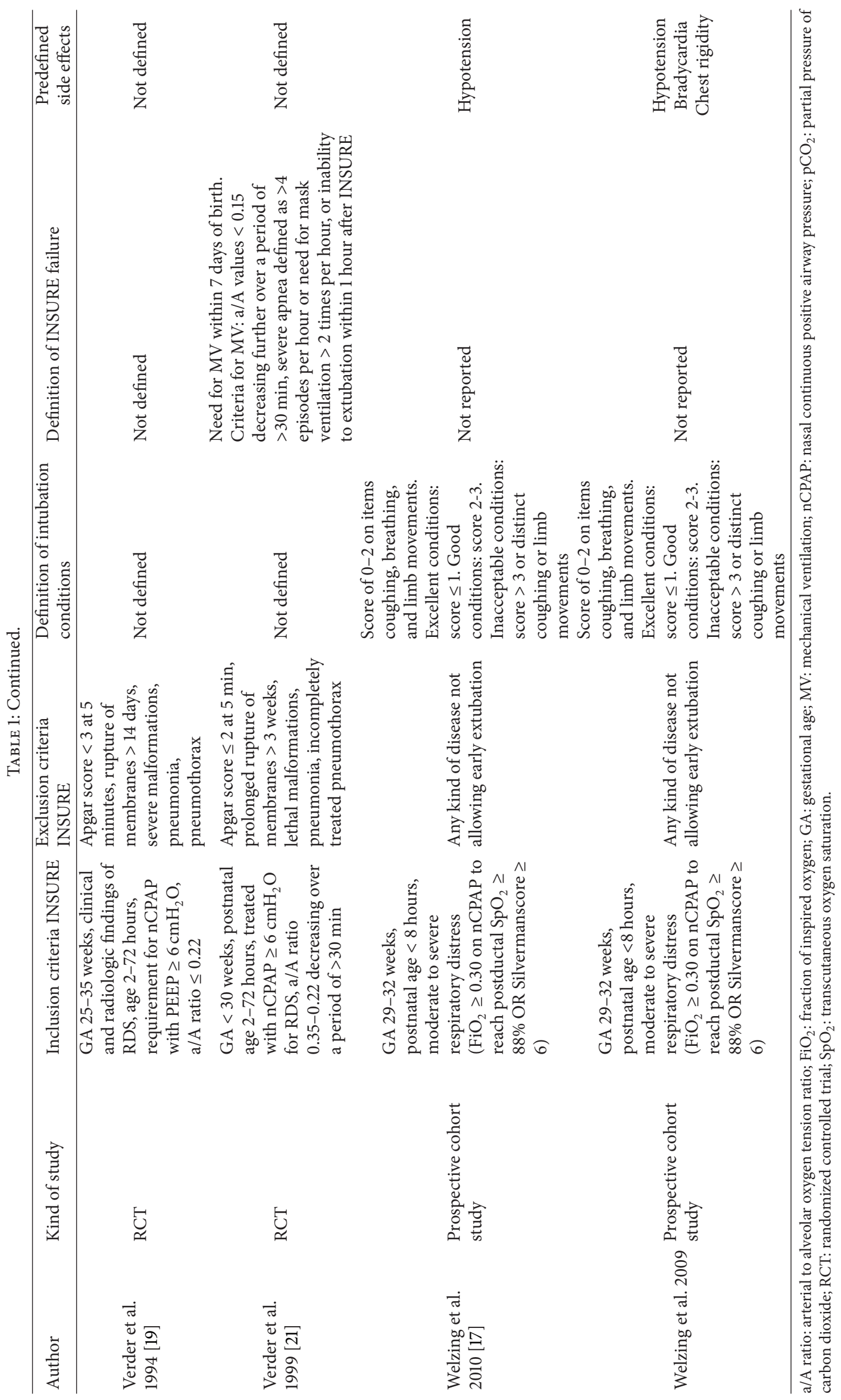




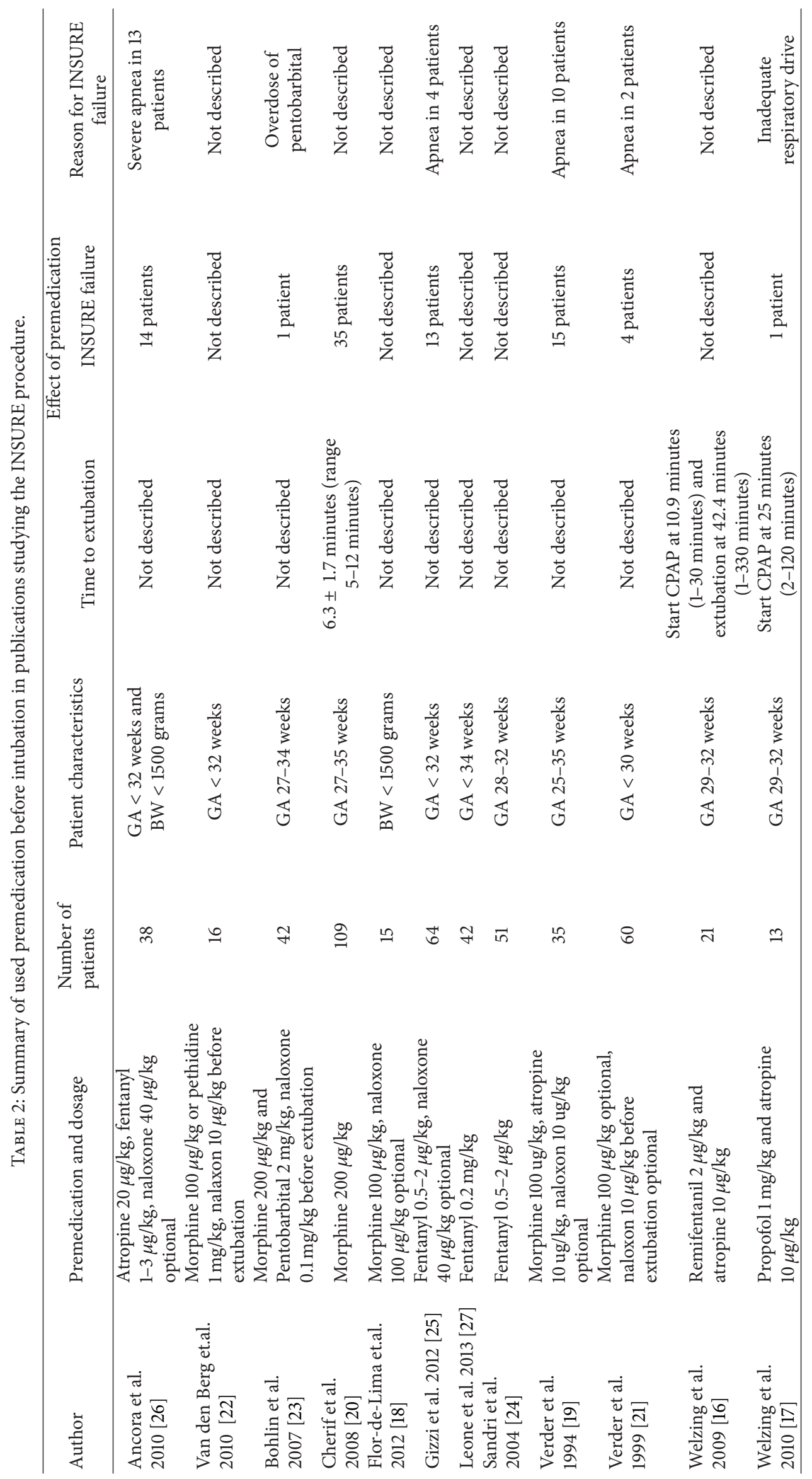


mention time to extubation but did mention INSURE failure in 15 patients (43\%): 2 patients could not be extubated after surfactant administration and another 13 patients had to be reintubated. In 10 of these 15 patients the reason for INSURE failure was recurrent apnea. Information regarding the time frame between extubation and INSURE failure was lacking [19]. In another study Verder et al. found that 4 patients (7\%) could not be extubated after surfactant administration. In two patients the reason was intractable apnea, which is a side effect of morphine. In this study the use of morphine was optional and the authors did not mention if these two patients had received morphine [21].

In the study of Bohlin et al., patients received a combination of $200 \mu \mathrm{g} / \mathrm{kg}$ morphine and $2 \mathrm{mg} / \mathrm{kg}$ pentobarbital prior to intubation. $100 \mu \mathrm{g} / \mathrm{kg}$ Naloxone was administered to all patients before extubation. Information regarding intubation conditions, number of attempts, and extubation time was not provided. Eight patients (19\%) could not be extubated after surfactant administration. This was related to the premedication in only one patient, who received an overdose of pentobarbital [23].

3.4. Fentanyl. Four studies used fentanyl as premedication; two studies at a dose of $0.5-2 \mu \mathrm{g} / \mathrm{kg}[24,25]$, one study at a dose of $1-3 \mu \mathrm{g} / \mathrm{kg}$ [26], and one study at a dose of $0.2 \mathrm{mg} / \mathrm{kg}$ [27]. None of these four studies detailed the intubation conditions, number of intubation attempts, and time to return of spontaneous breathing and extubation. The studies of Sandri et al. and Leone et al. also provided no information about INSURE failure [24, 27]. In the study of Gizzi et al. INSURE failed in 11 patients (35\%) who were extubated to nasal CPAP. In 4 patients the reason for INSURE failure was intractable apnea and the time frame between surfactant administration and INSURE failure was 48.1 hours (range 572 hours). In patients who were extubated to NIPPV, INSURE failed in 2 patients (6\%) on account of increased oxygen requirement [25]. Ancora et al. reported INSURE failure in 14 patients (37\%), on account of insufficient respiratory drive in 13 patients. INSURE failure occurred at a mean of 99 hours (range 1-150 hours) after extubation [26]. None of the studies reported the necessity of Naloxone therapy after fentanyl.

\section{Discussion}

Although the need of premedication before neonatal intubation is well recognized, there is no consensus on the most effective sedative to eliminate pain, discomfort, and physiologic instability and to provide conditions for rapid and safe intubations without adverse effects. Moreover, duration of action must be as short as possible to allow for a sufficient breathing pattern within several minutes after surfactant administration, so that extubation can be performed as quickly as possible (see Figure 1). This review found that only 2 pharmacological studies evaluated the effect of premedication for the INSURE procedure, that is, remifentanil and propofol.

Remifentanil, a synthetic opioid, was introduced into clinical practice in 1996 and is therefore the newest opioid

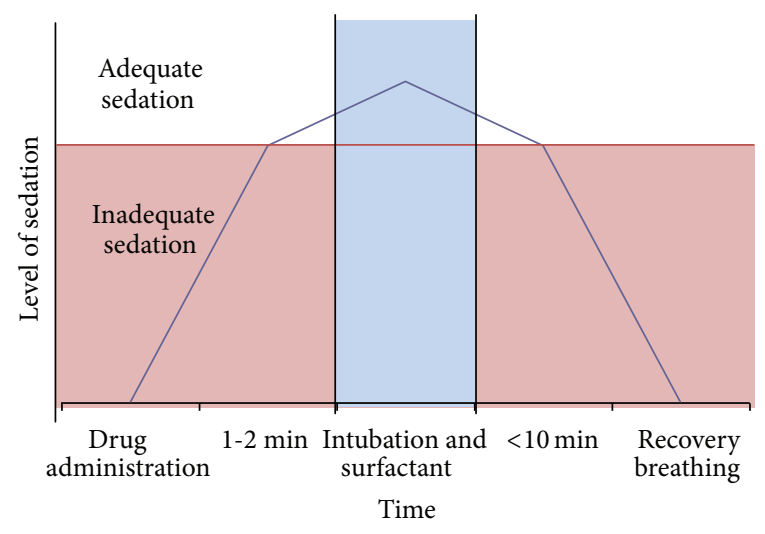

FIGURE 1: Ideal sedation model for the INSURE procedure.

available [28, 29]. Because of hydrolysis by nonspecific tissue and plasma esterases, metabolism is not dependent on liver and renal function, and metabolism is not age related [30-34]. Metabolism produces a metabolite known as remifentanil acid, which has no clinical significant activity $[29,31,32]$. This unique pharmacokinetic profile provides ultrashort action, high predictability, rapid onset and offset of action, immediate recovery of the clinical effect after interruption of the administration, a short context-sensitive half-life and short elimination time not influenced by the infusion time, and no accumulation of the drug [30, 31]. These positive effects of remifentanil were evident in several reviewed studies [32-39].

Choong et al. investigated the effect of remifentanil as premedication in neonatal elective intubations. They found good intubation conditions (using a seven-point Likert scale) and few intubation attempts were needed. Mean time to return of spontaneous respiration in those patients who did not receive any additional drugs besides remifentanil was 210 seconds [30]. This finding supports our hypothesis that remifentanil is suitable for the INSURE procedure. In the study of Welzing et al. remifentanil was also found to be effective for neonatal intubation. Intubation conditions were good or excellent in all patients and the vast majority of patients were intubated at the first attempt [16]. However, the authors' conclusions about the very short period of respiratory depression and early reinstitution of CPAP after surfactant treatment are debatable. The time to extubation was rather long (42.4 minutes and still 16.9 minutes after excluding 3 patients on prolonged endotracheal CPAP for logistic reasons) and does not perfectly meet the criterion of immediate extubation. To our opinion it therefore feels somewhat preliminary to state that remifentanil is an appropriate sedative to use as premedication for neonatal intubation during the INSURE procedure. Reduced clearance of remifentanil in the first postnatal days could probably explain the prolonged effect, and it would seem desirable to evaluate lower remifentanil doses that have not yet been studied. More research with remifentanil during the INSURE procedure in a larger group of preterm infants of variable gestational ages is needed. 
Propofol is a short acting single-use anaesthetic that is rapid in onset and short in duration and can preserve spontaneous respirations [40]. It is a highly lipophilic compound and exhibits rapid distribution from blood into subcutaneous fat and the central nervous system with subsequent redistribution. Propofol clearance mainly depends on hepatic blood flow with subsequent metabolism. Although multiple hepatic and extrahepatic human cytochrome p450 isoforms are involved in propofol metabolism, glucuronidation is the major metabolic pathway [41]. A study of Ghanta et al. found that, with the use of propofol $2.5 \mathrm{mg} / \mathrm{kg}$, successful intubation was reached twice as fast as with the combination of morphine, atropine, and suxamethonium, fewer attempts were needed, and patients regained spontaneous movements twice as fast [12].

Nevertheless, several studies have shown reduced propofol clearance notably in preterm neonates and neonates in the first 10 days of life, leading to accumulation of the drug during continuous infusion and bolus administration. Preterm neonates and neonates in the first 10 days of life are even more prone to display reduced clearance. After correcting for postmenstrual age and postnatal age, there is still extensive unexplained interindividual variability in propofol clearance in neonates, making prediction in neonates more difficult [40-43].

Welzing et al. evaluated the effect of propofol in a dose of $1 \mathrm{mg} / \mathrm{kg}$ in 13 patients undergoing INSURE. Propofol seemed to be very suitable and provided excellent or good intubation conditions in most patients and a very short period of respiratory depression [17]. We feel, however, that the 25 minutes' time to extubation is too long. Also, one patient needed reintubation because of insufficient breathing. Again, the rather long time to extubation may be explained perhaps by reduced clearance of propofol in preterm infants in the first 10 days of life which leads to longer duration of the sedative effect. Dose-finding studies in preterm infants of different gestational and postnatal ages should be performed to determine the right dose of propofol for different gestational and postnatal ages.

Further concerns about propofol in preterm neonates include the relatively high incidence of side effects, especially profound hypotension. The pilot study of Welzing et al. was stopped prematurely because of significant hypotension in 5 patients [17]. The relatively long lasting sedation and high incidence of hypotension point at excessive propofol doses. Evidence on the hypotensive side effect of propofol is not consistent: some studies report relatively high frequencies of hypotension [40,44-46], but this is not confirmed by others [12, 31, 47]. Vanderhaegen et al. studied the cerebral and systemic hemodynamic effects of propofol in neonates and found a short lasting decrease in cerebral oxygenation of several minutes and a decrease in mean arterial blood pressure up to 1 hour after propofol administration [40]. Possible age-related propofol dose response of neonates needs further exploration. The adequate propofol doses that provide good sedation, no hypotension or decreased cerebral perfusion, and fast restoration of sufficient breathing have yet to be found. Also, more research on the adequate doses of propofol for different gestational age groups during the
INSURE procedure is needed. Once known, propofol should be compared with remifentanil in a randomized controlled manner, to evaluate which drug would be the best with the fewest side effects.

Of all other 10 publications describing the INSURE procedure, only the one by Cherif et al., on morphine, reported a time to extubation, that is, $6.3 \pm 1.7$ minutes (range 5-12 minutes) [20]. Based on the PK/PD profile of morphine in newborns this seems to be quite short and morphine might not even have reached Pmax, also in view of the fact that INSURE failed in $32 \%$ of patients. This may have been due to recurrent apnea due to opioid induced respiratory depression. All other nine studies do not mention time to awakening and extubation but some of the studies mention INSURE failure because of intractable apneas $[19,21,23,24$, 26]. Opioid induced respiratory depression probably was the cause of these apneas.

Morphine has several limitations, notably delayed onset and prolonged duration of action, on account of which it is unsuitable to be used as a sedative in neonatal intubation $[6,11,36]$. This is confirmed by several studies. Lemyre et al. performed a randomized placebo controlled trial of morphine and found no differences between morphine and placebo in duration of distortion of vital parameters, duration of the intubation procedure, and number of attempts [48]. Several other studies compared morphine with other premedication regimens and unanimously found that morphine was less effective, providing worse intubation conditions and necessitating a greater number of attempts [12, 36, 49]. The prolonged duration of action of morphine could be antagonized with naloxone. However, naloxone also antagonizes endorphins and results in a direct very distressful condition and has the potential to cause cardiac arrest, as reported in an extremely preterm infant and two adult patients [50]. Also, the duration of action of naloxone is much shorter than that of morphine. Therefore, opioid induced respiratory depression antagonized with naloxone can easily return after the effect of naloxone has worn off. All this makes clear that morphine should not be used as premedication in neonatal intubation, especially during the INSURE procedure. Short acting opioids therefore probably are more suitable.

Other short acting drugs or combinations of drugs that could theoretically be used as rapid sequence induction for the INSURE procedure, such as midazolam or remifentanil combined with propofol or with thiopental, have not been reported in the literature yet [51].

\section{Conclusion}

In conclusion, propofol and remifentanil both have a very short onset and duration of action and are in theory the most suitable candidates for INSURE procedure premedication. However, only two relatively small studies have evaluated the effects of propofol and remifentanil in this context and insufficient data is available about optimal dosing, effects, and side effects. Therefore, more research including dose-finding studies and randomized controlled trials that compare different drugs are necessary. Morphine should be considered 
unsuitable for its delayed onset and prolonged period of action. This literature review revealed too little information to draw a solid conclusion.

\section{Abbreviations}

BIPAP: Bilevel positive airway pressure

BPD: Bronchopulmonary dysplasia

BW: Birth weight

CI: Confidence interval

GA: Gestational age

nCPAP: Nasal continuous positive airway pressure

NICU: Neonatal intensive care unit

NIPPV: Nasal intermittent positive pressure ventilation

PK/PD: Pharmacokinetic and pharmacodynamic

RDS: Respiratory distress syndrome

RR: $\quad$ Relative risk.

\section{Conflict of Interests}

The authors declare that there is no conflict of interests regarding the publication of this paper. Sinno H. P. Simons received a personal Grant from The Netherlands Organisation for Health Research and Development (ZonMw 90713494).

\section{References}

[1] S. H. P. Simons, M. van Dijk, K. S. Anand, D. Roofthooft, R. A. van Lingen, and D. Tibboel, "Do we still hurt newborn babies? A prospective study of procedural pain and analgesia in neonates," Archives of Pediatrics and Adolescent Medicine, vol. 157, no. 11, pp. 1058-1064, 2003.

[2] S. Sarkar, R. E. Schumacher, S. Baumgart, and S. M. Donn, "Are newborns receiving premedication before elective intubation?" Journal of Perinatology, vol. 26, no. 5, pp. 286-289, 2006.

[3] S. Whyte, G. Birrell, and J. Wyllie, "Premedication before intubation in UK neonatal units," Archives of Disease in Childhood: Fetal and Neonatal Edition, vol. 82, no. 1, pp. F38-F41, 2000.

[4] E. Byrne and R. MacKinnon, "Should premedication be used for semi-urgent or elective intubation in neonates?" Archives of Disease in Childhood, vol. 91, no. 1, pp. 79-83, 2006.

[5] J. Oei, R. Hari, T. Butha, and K. Lui, "Facilitation of neonatal nasotracheal intubation with premedication: a randomized controlled trial," Journal of Paediatrics and Child Health, vol. 38, no. 2, pp. 146-150, 2002.

[6] P. Kumar, S. E. Denson, T. J. Mancuso et al., "Premedication for nonemergency endotracheal intubation in the neonate," Pediatrics, vol. 125, no. 3, pp. 608-615, 2010.

[7] R. Carbajal, B. Eble, and K. J. S. Anand, "Premedication for tracheal intubation in neonates: confusion or controversy?" Seminars in Perinatology, vol. 31, no. 5, pp. 309-317, 2007.

[8] L. Simon, M. Trifa, M. Mokhtari, J. Hamza, and J.-M. Treluyer, "Premedication for tracheal intubation: a prospective survey in 75 neonatal and pediatric intensive care units," Critical Care Medicine, vol. 32, no. 2, pp. 565-568, 2004.

[9] V. Venkatesh, V. Ponnusamy, J. Anandaraj et al., "Endotracheal intubation in a neonatal population remains associated with a high risk of adverse events," European Journal of Pediatrics, vol. 170, no. 2, pp. 223-227, 2011.
[10] R. Chaudhary, S. Chonat, H. Gowda, P. Clarke, and A. Curley, "Use of premedication for intubation in tertiary neonatal units in the United Kingdom," Paediatric Anaesthesia, vol. 19, no. 7, pp. 653-658, 2009.

[11] J. Kelleher, P. Mallya, and J. Wyllie, "Premedication before intubation in UK neonatal units: a decade of change?" Archives of Disease in Childhood: Fetal and Neonatal Edition, vol. 94, no. 5, pp. F332-F335, 2009.

[12] S. Ghanta, M. E. Abdel-Latif, K. Lui, H. Ravindranathan, J. Awad, and J. Oei, "Propofol compared with the morphine, atropine, and suxamethonium regimen as induction agents for neonatal endotracheal intubation: a randomized, controlled trial," Pediatrics, vol. 119, no. 6, pp. e1248-e1255, 2007.

[13] B. Lemyre, R. Cheng, and I. Gaboury, "Atropine, fentanyl and succinylcholine for non-urgent intubations in newborns," Archives of Disease in Childhood: Fetal and Neonatal Edition, vol. 94, no. 6, pp. F439-F442, 2009.

[14] D. G. Sweet, V. Carnielli, G. Greisen et al., "European consensus guidelines on the management of neonatal respiratory distress syndrome in preterm infants-2013 update," Neonatology, vol. 102, pp. 353-368, 2013.

[15] T. P. Stevens, E. W. Harrington, M. Blennow, and R. F. Soll, "Early surfactant administration with brief ventilation vs. selective surfactant and continued mechanical ventilation for preterm infants with or at risk for respiratory distress syndrome," Cochrane Database of Systematic Reviews, no. 4, Article ID CD003063, 2007.

[16] L. Welzing, A. Kribs, C. Huenseler, F. Eifinger, K. Mehler, and B. Roth, "Remifentanil for INSURE in preterm infants: a pilot study for evaluation of efficacy and safety aspects," Acta Paediatrica, vol. 98, no. 9, pp. 1416-1420, 2009.

[17] L. Welzing, A. Kribs, F. Eifinger, C. Huenseler, A. Oberthuer, and B. Roth, "Propofol as an induction agent for endotracheal intubation can cause significant arterial hypotension in preterm neonates," Paediatric Anaesthesia, vol. 20, no. 7, pp. 605-611, 2010.

[18] F. Flor-de-Lima, G. Rocha, and H. Guimaraes, "Impact of changes in perinatal care on neonatal respiratory outcome and survival of preterm newborns: an overview of 15 years," Critical Care Research and Practice, vol. 2012, Article ID 643246, 7 pages, 2012.

[19] H. Verder, B. Robertson, G. Greisen et al., "Surfactant therapy and nasal continuous positive airway pressure for newborns with respiratory distress syndrome," The New England Journal of Medicine, vol. 331, no. 16, pp. 1051-1055, 1994.

[20] A. Cherif, C. Hachani, and N. Khrouf, "Risk factors of the failure of surfactant treatment by transient intubation during nasal continuous positive airway pressure in preterm infants," American Journal of Perinatology, vol. 25, no. 10, pp. 647-652, 2008.

[21] H. Verder, P. Albertsen, F. Ebbesen et al., "Nasal continuous positive airway pressure and early surfactant therapy for respiratory distress syndrome in newborns of less than 30 weeks' gestation," Pediatrics, vol. 103, no. 2, p. E24, 1999.

[22] E. van den Berg, P. M. A. Lemmers, M. C. Toet, J. H. G. Klaessens, and F. van Bel, "Effect of the "InSurE" procedure on cerebral oxygenation and electrical brain activity of the preterm infant," Archives of Disease in Childhood: Fetal and Neonatal Edition, vol. 95, no. 1, pp. F53-F58, 2010.

[23] K. Bohlin, T. Gudmundsdottir, M. Katz-Salamon, B. Jonsson, and M. Blennow, "Implementation of surfactant treatment 
during continuous positive airway pressure," Journal of Perinatology, vol. 27, no. 7, pp. 422-427, 2007.

[24] F. Sandri, G. Ancora, A. Lanzoni et al., "Prophylactic nasal continuous positive airways pressure in newborn of 28-31 weeks gestation: multicentre randomised controlled clinical trial," Archives of Disease in Childhood: Fetal and Neonatal Edition, vol. 89, no. 5, pp. F394-F398, 2004.

[25] C. Gizzi, P. Papoff, I. Giordano et al., "Flow-synchronized nasal intermittent positive pressure ventilation for infants $<32$ weeks' gestation with respiratory distress syndrome," Critical Care Research and Practice, vol. 2012, Article ID 301818, 7 pages, 2012.

[26] G. Ancora, E. Maranella, S. Grandi, L. Pierantoni, M. Guglielmi, and G. Faldella, "Role of bilevel positive airway pressure in the management of preterm newborns who have received surfactant," Acta Paediatrica, vol. 99, no. 12, pp. 1807-1811, 2010.

[27] F. Leone, D. Trevisanuto, F. Cavallin, M. Parotto, and V. Zanardo, "Efficacy of INSURE during nasal CPAP in preterm infants with respiratory distress syndrome," Minerva Pediatrica, vol. 65, pp. 187-192, 2013.

[28] M. G. Penido, D. F. de Oliveira Silva, E. C. Tavares, and Y. Pereira e Silva, "Propofol versus midazolam for intubating preterm neonates: a randomized controlled trial," Journal of Perinatology, vol. 31, no. 5, pp. 356-360, 2011.

[29] P. J. Davis and F. P. Cladis, "The use of ultra-short-acting opioids in paediatric anaesthesia the role of remifentanil," Clinical Pharmacokinetics, vol. 44, no. 8, pp. 787-796, 2005.

[30] K. Choong, K. Alfaleh, J. Doucette et al., "Remifentanil for endotracheal intubation in neonates: a randomised controlled trial," Archives of Disease in Childhood: Fetal and Neonatal Edition, vol. 95, no. 2, pp. F80-F84, 2010.

[31] M. G. Penido, R. Garra, M. Sammartino, and Y. Pereira e Silva, "Remifentanil in neonatal intensive care and anaesthesia practice," Acta Paediatrica, vol. 99, no. 10, pp. 1454-1463, 2010.

[32] L. Welzing and B. Roth, "Experience with remifentanil in neonates and infants," Drugs, vol. 66, no. 10, pp. 1339-1350, 2006.

[33] P. Lago, C. Tiozzo, G. Boccuzzo, A. Allegro, and F. Zacchello, "Remifentanil for percutaneous intravenous central catheter placement in preterm infant: a randomized controlled trial," Paediatric Anaesthesia, vol. 18, no. 8, pp. 736-744, 2008.

[34] C. Giannantonio, M. Sammartino, E. Valente, F. Cota, M. Fioretti, and P. Papacci, "Remifentanil analgosedation in preterm newborns during mechanical ventilation," Acta Paediatrica, vol. 98, no. 7, pp. 1111-1115, 2009.

[35] Y. Pereira e Silva, R. S. Gomez, J. de Oliveira Marcatto, T. A. Maximo, R. Ferreira Barbosa, and A. C. Simoes e Silva, "Early awakening and extubation with remifentanil in ventilated premature neonates," Paediatric Anaesthesia, vol. 18, no. 2, pp. 176$183,2008$.

[36] Y. Pereira e Silva, R. S. Gomez, J. de Oliveira Marcatto, T. A. Maximo, R. Ferreira Barbosa, and A. C. Simoes e Silva, "Morphine versus remifentanil for intubating preterm neonates," Archives of Disease in Childhood: Fetal and Neonatal Edition, vol. 92, no. 4, pp. F293-F294, 2007.

[37] M. Sammartino, M. G. Bocci, G. Ferro et al., "Efficacy and safety of continuous intravenous infusion of remifentanil in preterm infants undergoing laser therapy in retinopathy of prematurity: clinical experience," Paediatric Anaesthesia, vol. 13, no. 7, pp. 596-602, 2003.

[38] M. Sammartino, R. Garra, F. Sbaraglia, M. De Riso, N. Continolo, and P. Papacci, "Experience of remifentanil in extremely low-birth-weight babies undergoing laparotomy," Pediatrics and Neonatology, vol. 52, no. 3, pp. 176-179, 2011.
[39] Y. Pereira e Silva, R. S. Gomez, R. Ferreira Barbosa, and A. C. Simoes e Silva, "Remifentanil for sedation and analgesia in a preterm neonate with respiratory distress syndrome," Paediatric Anaesthesia, vol. 15, no. 11, pp. 993-996, 2005.

[40] J. Vanderhaegen, G. Naulaers, S. van Huffel, C. Vanhole, and K. Allegaert, "Cerebral and systemic hemodynamic effects of intravenous bolus administration of propofol in neonates," Neonatology, vol. 98, no. 1, pp. 57-63, 2010.

[41] K. Allegaert, M. Y. Peeters, R. Verbesselt et al., "Inter-individual variability in propofol pharmacokinetics in preterm and term neonates," British Journal of Anaesthesia, vol. 99, no. 6, pp. 864870, 2007.

[42] L. Thewissen and K. Allegaert, "Analgosedation in neonates: do we still need additional tools after 30 years of clinical research?" Archives of Disease in Childhood: Education and Practice Edition, vol. 96, no. 3, pp. 112-118, 2011.

[43] K. Allegaert, M. Y. Peeters, and C. Knibbe, "Propofol in (pre)term neonates: consider the extensive interindividual variability in clearance within the neonatal population," Paediatric Anaesthesia, vol. 21, no. 2, pp. 174-175, 2011.

[44] S. H. P. Simons, R. van der Lee, I. K. Reiss, and M. Weissenbruch, "Clinical evaluation of propofol as sedative for endotracheal intubation in neonates," Acta Paediatrica, vol. 102, pp. e487e492, 2013.

[45] P. Papoff, M. Mancuso, E. Caresta, and C. Moretti, "Effectiveness and safety of propofol in newborn infants," Pediatrics, vol. 121, no. 2, pp. 448-449, 2008.

[46] F. Veyckemans, "Propofol for intubation of the newborn?" Paediatric Anaesthesia, vol. 11, no. 5, pp. 630-631, 2001.

[47] M. Nauta, W. Onland, and A. De Jaegere, "Propofol as an induction agent for endotracheal intubation can cause significant arterial hypotension in preterm infants," Paediatric Anaesthesia, vol. 21, no. 6, pp. 711-712, 2011.

[48] B. Lemyre, J. Doucette, A. Kalyn, S. Gray, and M. L. Marrin, "Morphine for elective endotracheal intubation in neonates: a randomized trial," BMC Pediatrics, vol. 4, article 20, 2004.

[49] E. Norman, S. Wikström, L. Hellström-Westas, U. Turpeinen, E. Hämäläinen, and V. Fellman, "Rapid sequence induction is superior to morphine for intubation of preterm infants: a randomized controlled trial," Journal of Pediatrics, vol. 159, no. 6, pp. 893-899, 2011.

[50] G. Deshpande and A. Gill, "Cardiac arrest following naloxone in an extremely preterm neonate," European Journal of Pediatrics, vol. 168, no. 1, pp. 115-117, 2009.

[51] E. Norman, S. Wikström, L. Hellström-Westas, U. Turpeinen, E. Hämäläinen, and V. Fellman, "Rapid sequence induction is superior to morphine for intubation of preterm infants: a randomized controlled trial," Journal of Pediatrics, vol. 159, no. 6, pp. 893-899, 2011. 

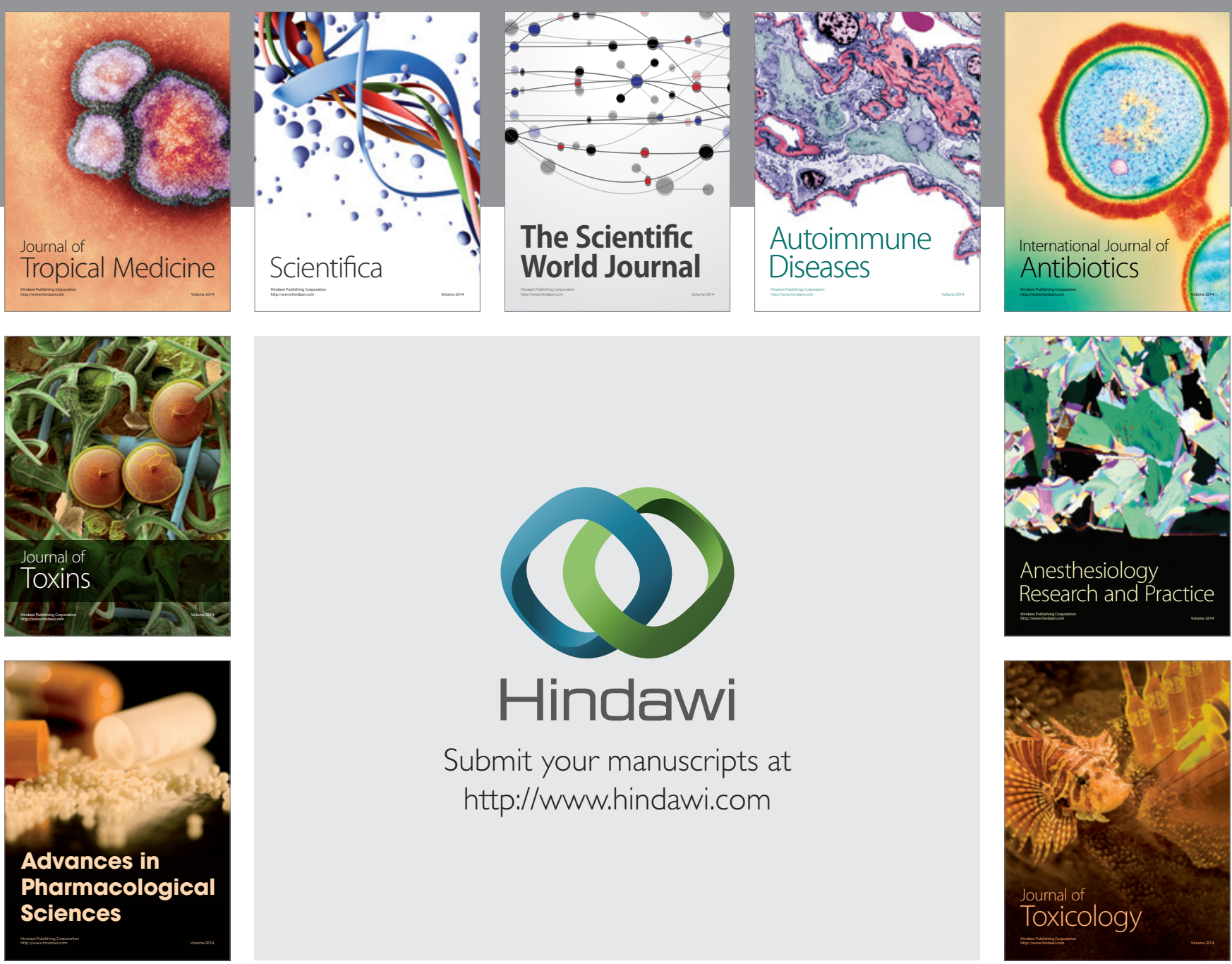

\section{Hindawi}

Submit your manuscripts at

http://www.hindawi.com
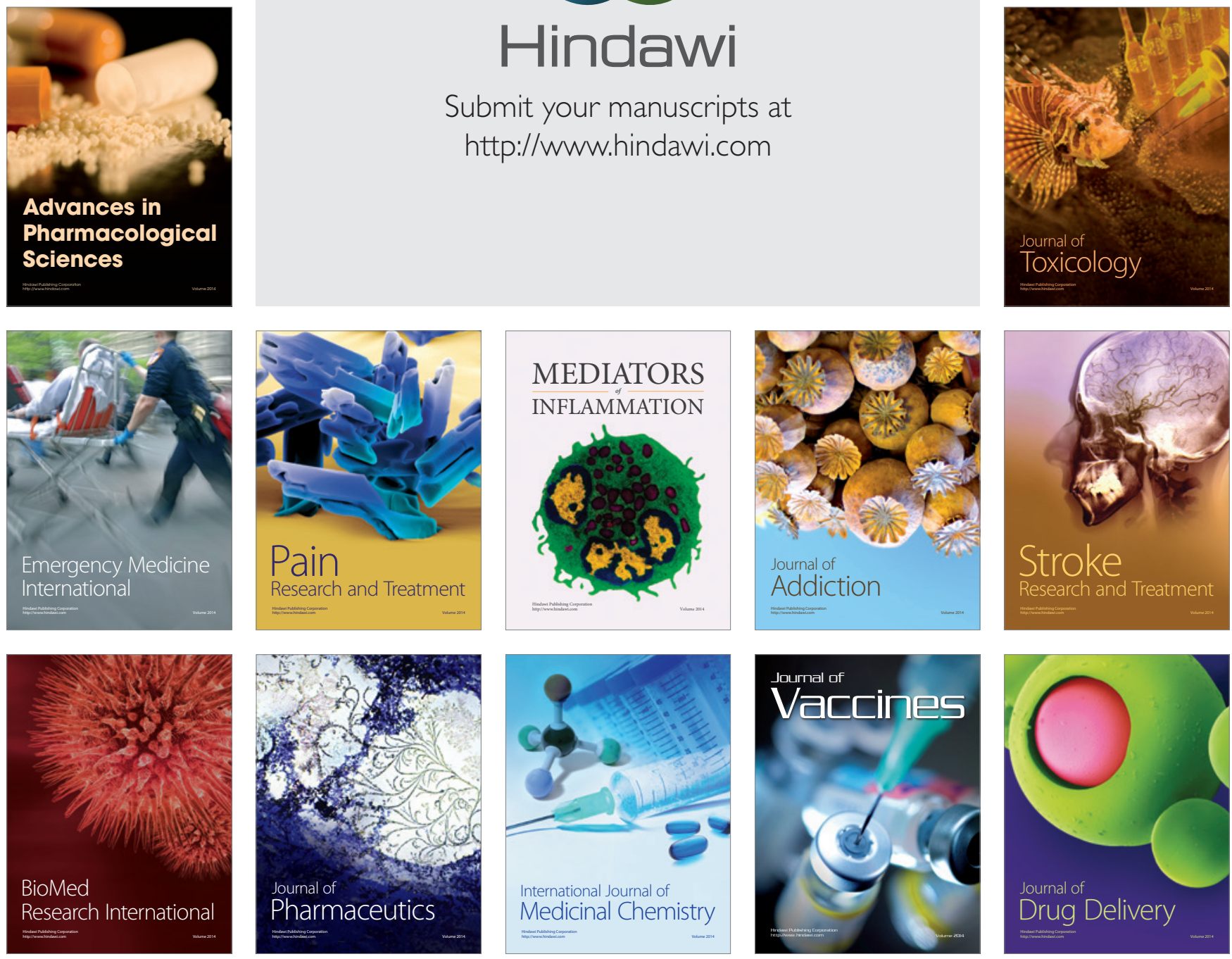